\title{
Formation of Polychlorinated Dibenzo-p-Dioxins and Polychlorinated Dibenzofurans and Their Precursors in Fires of Pyrethroid Pesticide Alpha-Cypermethrin
}

\author{
SINDRA L. SUMMOOGUM ${ }^{1}$, DOMINIKA A. WOJTALEWICZ ${ }^{1}$, JOHN C. MACKIE ${ }^{1,2}$, ERIC M. \\ KENNEDY ${ }^{1}$, and BOGDAN Z. DLUGOGORSKI ${ }^{1}$ \\ ${ }^{1}$ Process Safety and Environmental Protection Group \\ School of Engineering \\ The University of Newcastle, Callaghan, NSW 2308, Australia \\ ${ }^{2}$ School of Chemistry \\ The University of Sydney \\ NSW 2006, Australia
}

\begin{abstract}
This study reports the results of the gas phase oxidation of alpha-cypermethrin, a common insecticide, elucidating the decomposition pathways and formation of toxic species such as polychlorinated dibenzo-pdioxins and polychlorinated dibenzofurans $(\mathrm{PCDD} / \mathrm{F})$ and their precursors. Conditions investigated are similar to those encountered in post combustion and cooling-down zones of forest, agricultural and wild fires, as well as in burning of biomass contaminated or treated with pesticides. The experiments were conducted under fuel lean conditions in a tubular reactor housed in a three-zone heating furnace and operated with a dilute stream of alpha-cypermethrin in ultra high purity nitrogen and oxygen. PCDD/F were identified and quantified by high resolution gas chromatography (HRGC)-ion trap mass spectrometry (ITMS). We detected mono to hepta chlorinated dibenzo- $p$-dioxins and dibenzofurans with maximum emission factors of $141 \quad \mu \mathrm{g} \mathrm{g} \mathrm{g}^{-1}$ and $384 \quad \mathrm{pg} \quad \Sigma$ TEQ-WHO $2005 \quad \mathrm{~g}^{-1}$ of alpha-cypermethrin. 1-monochlorodibenzofuran was ranked as the most abundant congener. We also conducted the analyses of volatile organic compounds (VOC) attempting to identify the PCDD/F precursors by means of HRGCquadrupole mass spectrometry (QMS). The results of VOC revealed chlorobenzene, diphenyl ether, benzaldehyde, chlorotoluene, dichlorotoluene as important PCDD/F precursors.
\end{abstract}

KEYWORDS: toxicity, polychlorinated dibenzo-p-dioxins, polychlorinated dibenzofurans, wildfires, emission factors.

\section{INTRODUCTION}

Belonging to the pyrethroid group of insecticides, alpha-cypermethrin is used for a wide range of domestic and agricultural applications such as sprays and insect coils. In general, the pyrethroids have been developed synthetically from the naturally occurring compound pyrethrum to preserve the toxicity of the natural species and to enhance their stability in sunlight. Their recent increase in popularity can be attributed to their effectiveness and potency in combating Lyctine borers and termites at low concentrations [1-3]. Alpha-cypermethrin is a highly active broad-spectrum insecticide, effective by contact and ingestion against target pests. It is widely used for protection of agricultural crops, forests, and in domestic applications due to its short field life.

Owing to their substantial use, pyrethroids are frequently handled in large quantities during production and storage, with pesticide fires reported to occur during these activities. The fires result in the release of significant amounts of toxic pollutants such as polychlorinated dibenzo-p-dioxins (PCDD) and polychlorinated dibenzofurans (PCDF); in combination these chemicals are denoted as PCDD/F or dioxins. PCDD/F exhibit similar chemical properties and are primarily formed as unwanted pollutant by-products in many thermal processes. PCDD/F are of great concern due to their environmental persistence, toxicity and bioaccumulation through the food chain. Taking into consideration these criteria, we selected alphacypermethrin, with rapidly growing production and use in the pyrethroids market, to investigate its behaviour in fires; especially, its propensity to form precursors that act to produce PCDD/F in fires. 
The hazards of accidental chemical fires which may occur in production and storage facilities necessitate a better understanding of toxic species. Recent incidents, namely the bushfires events in the USA and Australia also motivate efforts in analysing toxic products. Burning of pesticide bags and forest fires constitute a significant source of dioxins on a global scale, contributing appreciably to dioxin inventories of $9.0 \times 10^{-3}$ and $2.0 \times 10^{-3}-5.6 \times 10^{-2} \Sigma \mathrm{TEQ}-\mathrm{WHO}_{1998} \mathrm{ng} \mathrm{g}^{-1}$, respectively [4]. Under fire conditions, dioxins compounds are emitted near the ground level and are deposited near the emission sources unlike the case in incineration where tall stacks promote distant transport of pollutants. Therefore, dioxins emission from fire sources is likely to have a local effect in the vicinity of the emission source. Moreover, fires provide favourable conditions, namely temperature and oxygen environments to produce PCDD/F. Oxygen is necessary for PCDD/F formation from macromolecular carbon, and consequently, several research groups have focussed on the effect of the concentration of $\mathrm{O}_{2}$ in the reactant stream. The results indicate that a reduced oxygen concentration is more conducive to the formation of $\mathrm{PCDD} / \mathrm{F}$, with maximum rates occurring for gas-phase concentration of 5 to $10 \% \mathrm{O}_{2}$, as described by Addink and co-researchers [5].

Unfortunately the present understanding of mechanisms of PCDD/F formation in the combustion of pesticides is quite inadequate, compared to those of chlorinated naphthalenes, diphenyl ether, dibenzofurans, biphenyls, chlorobenzene, chlorophenol and PVC [6-14]. While the thermal decomposition of alpha-cypermethrin has been studied, no publication has examined the formation of PCDD/F from this pesticide. For this reason, in the current work, we aim to elucidate the formation of pollutants during the thermal decomposition of alpha-cypermethrin at $550{ }^{\circ} \mathrm{C}$ in oxygen rich atmosphere, with the ultimate objective to gain a better understanding of the formation of PCDD/F species and their precursors in fires. We follow the work of Addink et al. [5] and Tame et al. [3] to select oxygen concentration of 5.5 ( \pm 0.5$) \%$ for the present study. We also aim to obtain realistic estimates of the maximum emission factors of $\mathrm{PCDD} / \mathrm{F}$ pollutants from fires involving alpha-cypermethrin. Finally, in this article, we describe the formation of PCDD/F precursors, and discuss mechanistic pathways leading to formation of the major congeners of PCDD/F.

\section{EXPERIMENTAL}

\section{Description of Experimental Facility}

The experiments involved generating a dilute stream of alpha-cypermethrin for oxidation in a tubular reactor as shown in Fig. 1 and with the details of the apparatus described elsewhere [15-18].

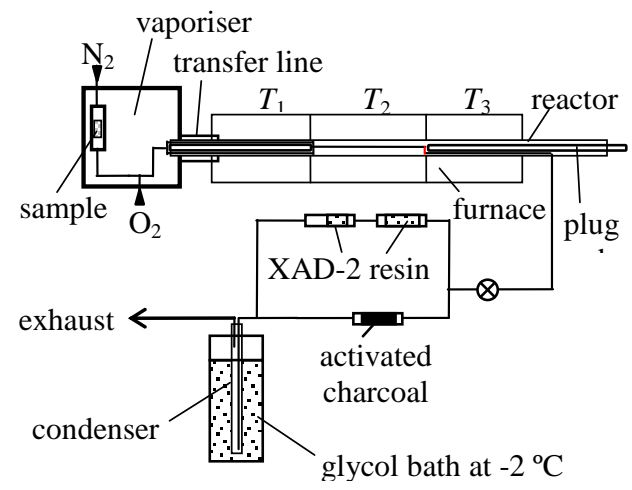

Fig.1. Sketch of the experimental set-up.

The pesticide was loaded inside a ceramic tube which was installed vertically in a vaporiser and heated at $190{ }^{\circ} \mathrm{C}$ to evaporate slowly under the flow of pure nitrogen $(99.999 \%)$. Oxygen mixed was with the vapour $/ \mathrm{N}_{2}$ stream prior to entering the reactor, resulting in an $\mathrm{O}_{2}$ concentration of $5.5( \pm 0.5) \%$ in $\mathrm{N}_{2}(\mathrm{v} / \mathrm{v})$, with a total flow rate of $21.99 \mathrm{~cm}^{3} / \mathrm{min}$ and uniform mixing achieved by a plug of pre-cleaned glass wool. The average evaporation rate was measured as $0.04( \pm 10 \%) \mathrm{mg} \mathrm{min}^{-1}$ of alpha-cypermethrin, resulting in 
the fuel equivalence ratio of 0.04 . We performed the experiments using a tubular reactor made of alumina, $75 \mathrm{~cm}$ in length and $7.1 \mathrm{~mm}$ in internal diameter (i.d). The volume of the reactor was adjusted by inserting two rods, $5.4 \mathrm{~mm}$ in outside diameter (o.d), from both ends of the tube to ensure that the vapour reaches the reaction zone rapidly, through the annulus between the rod and the alumina tube, minimising alphacypermethrin decomposition in lower temperature regions. The experiment was performed at $550{ }^{\circ} \mathrm{C}$ and at two residence times, namely 1 and $5 \mathrm{~s}$. Prior to entering and after leaving the reactor, the gases flowed rapidly through the annular space between the rods and the alumina tube. Each experiment continued for 6 $\mathrm{h}$ with product gases flowing through two XAD-2 resin cartridges arranged in tandem (210 $\mathrm{mg}$ of resin in the front cartridge and $170 \mathrm{mg}$ in the back), as well as through a chilled impinger containing dichloromethane (DCM) and acetone. In separate experiments that involved sampling for $1 \mathrm{~h}$, the reactor's exit was coupled with a trap of activated carbon (approximately $100 \mathrm{mg}$ ) to intercept volatile organic compounds (VOC).

\section{Sample Clean-up and Preparation}

Initial experiments revealed that most dioxins condensed on the ceramic tubes and on PTFE tubes connected to the reactor. Least PCDD/F were adsorbed in the XAD-2 resin cartridges. All elements were extracted and purified separately before GC-MS analysis. XAD-2 resin was transferred to extraction thimbles, fortified with ${ }^{13} \mathrm{C}$-labelled standard of 17 toxic congeners of PCDD/F and extracted with toluene for $8 \mathrm{~h}$ in an automated extraction unit (Buchi). To collect the chemicals condensed on the reactor's walls and the PTFE tubes, we washed the ceramic and PTFE tubes with $20 \mathrm{~mL}$ solution of DCM and acetone $(1: 1 \mathrm{v} / \mathrm{v})$. To improve the quality of extraction of toxic species from the reactor's tube, in initial experiments, we washed the ceramic tube twice with the same amount of solvents and analysed the solvents separately. Since initial experiments proved that single extraction gave a recovery of $99 \%$ of analytes, we proceeded with single extraction for subsequent analyses. Extracts from ceramic and PTFE tubes were spiked with ${ }^{13} \mathrm{C}$-labelled standard of 17 toxic congeners of PCDD/F and cleaned-up using chromatography columns filled with acidic and basic silica gel and acidic and basic alumina. Likewise, the extracts of XAD-2 were cleaned-up with glass chromatography columns loaded with acidic and basic alumina. Subsequently, the cleaned-up solutions were concentrated to final volume, $20 \mu \mathrm{L}$ in decane, in a nitrogen stream and then analysed by the Varian 3800 GC and Saturn 2000 ITMS systems.

\section{Quality Assurance and Control}

To establish the limits of detection (LOD) and quantification (LOQ), we analysed solutions prepared in house from purchased standards (Wellington Laboratories and AccuStandard) namely (i) the solutions containing low concentrations $\left(0.5 \mathrm{pg} \mu \mathrm{L}^{-1}\right)$ of different MCDD/F to TriCDD/F congeners and (ii) 1613 CS1 standard from EPA 1613 calibration kit (Wellington Laboratories) containing 17 toxic PCDD/F

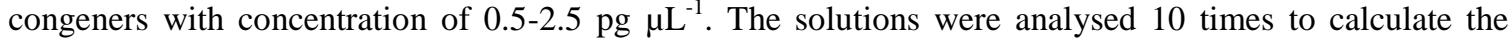
standard deviation (SD). The LOD and LOQ were taken to correspond to 3 and 10 times of SD respectively. The limits of detection of PCDD/F standards, analysed on our HRGC-ITMS instrument, correspond to between 0.2 and $3.6 \mathrm{pg} \mu \mathrm{L}^{-1}$ as listed in the Appendix.

The analyses of ${ }^{13} \mathrm{C}$-labelled PCDD/F recovery standards spiked into XAD-2 resin, ceramic and PTFE tubes prior to extraction and clean-up, yielded good recoveries of 55-86\%. A blank test was performed by extracting unexposed XAD-2 resin, with results displaying no presence of PCDD/F (signal/noise < 3). Monochlorinated DF was mainly trapped in the XAD-2 resins while the other congeners condensed, preferentially, both on the reactor's walls and on the PTFE tubes prior to the resin trap.

\section{Operating Parameters for GC-MS/MS Analyses}

The analysis of PCDD/F was performed on a Varian CP3800 GC coupled by a transfer line $\left(270{ }^{\circ} \mathrm{C}\right)$ to a Saturn 2000 (Varian) ion trap, operated in MS/MS mode. Samples of $1 \mu \mathrm{L}$ were introduced into an injector held at $280{ }^{\circ} \mathrm{C}$ operated in a splitless mode. Chromatographic separation was achieved with a VF-5ms capillary column $(60 \mathrm{~m}$ length, $0.25 \mathrm{~mm}$ i.d., $0.25 \mu \mathrm{m}$ film thickness) with helium as the carrier gas $\left(1 \mathrm{~mL} \min ^{-1}\right)$. The oven temperature program was held at $80^{\circ} \mathrm{C}$ for one min, then a rise to $235^{\circ} \mathrm{C}$ (held for 
$10 \mathrm{~min}$ ) at $10^{\circ} \mathrm{C} \min ^{-1}$, subsequent increase to $275{ }^{\circ} \mathrm{C}$ (held for $9 \mathrm{~min}$ ) at $5{ }^{\circ} \mathrm{C} \min ^{-1}$ and then to $310{ }^{\circ} \mathrm{C}$ (held for $6 \mathrm{~min}$ ) at $10^{\circ} \mathrm{C} \mathrm{min}^{-1}$. The ion trap and manifold temperatures were maintained at $200{ }^{\circ} \mathrm{C}$ and $80^{\circ} \mathrm{C}$, respectively. We optimised the method and have quantified PCDD/F with standards obtained from Wellington Laboratories (Ontario, Canada). Characteristic daughter ions for dioxins (parent minus $\mathrm{COCl}$ $(\mathrm{M}-\mathrm{COCl})$ ) were deployed for the quantification.

Regarding the analysis of VOC, we extracted the activated charcoal for 30 min with $\mathrm{CS}_{2}$. Each extract was transferred into a syringe fitted with a PTFE syringe filter and then injected into the Varian CP3800 high resolution gas chromatograph (HRGC) and Varian 1200 quadrupole mass spectrometer (QMS), equipped with a $30 \mathrm{~m}$ Varian VF-5ms column (i.d. of $0.25 \mathrm{~mm}$, film thickness of $0.25 \mu \mathrm{m}$ ). The GC oven temperature program included holding at $70{ }^{\circ} \mathrm{C}$ for $5 \mathrm{~min}$; heating at $10{ }^{\circ} \mathrm{C} \mathrm{min}{ }^{-1}$ to $235{ }^{\circ} \mathrm{C}$, holding for 10 min and finally heating at $10^{\circ} \mathrm{C} \mathrm{min}^{-1}$ to $280{ }^{\circ} \mathrm{C}$ with 5 min hold time. Helium served as a carrier gas at a

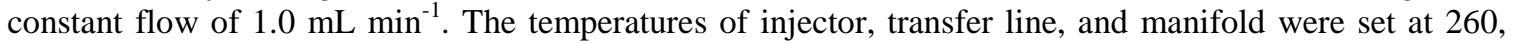
250 , and $150{ }^{\circ} \mathrm{C}$ respectively. The quadrupole mass spectrometer operated in the electron-impact mode with ionisation energy of $70 \mathrm{eV}$.

\section{RESULTS AND DISCUSSION}

The exhaust gases from the experiment carried out at $550{ }^{\circ} \mathrm{C}$ and a residence time of $1 \mathrm{~s}$ comprised a number of volatile organic compounds, in addition to $\mathrm{HCl}, \mathrm{HCN}$ and $\mathrm{CO}_{2}$. Figure 2 illustrates a typical chromatogram from GC-MS analysis of VOC, with products identified in the $\mathrm{CS}_{2}$ solution, as chlorobenzene $(\mathrm{CB})$, chlorotoluene isomers $(\mathrm{CT})$, benzaldehyde (BAL), benzonitrile $(\mathrm{BZN})$, benzofuran (BF), benzyl chloride (BC), methyl benzonitrile (MBZN), dichlorotoluene (DCT), and diphenyl ether (DPE). The identity of CB, BAL, BZN, BF and DPE were confirmed by the injection of authentic standards.
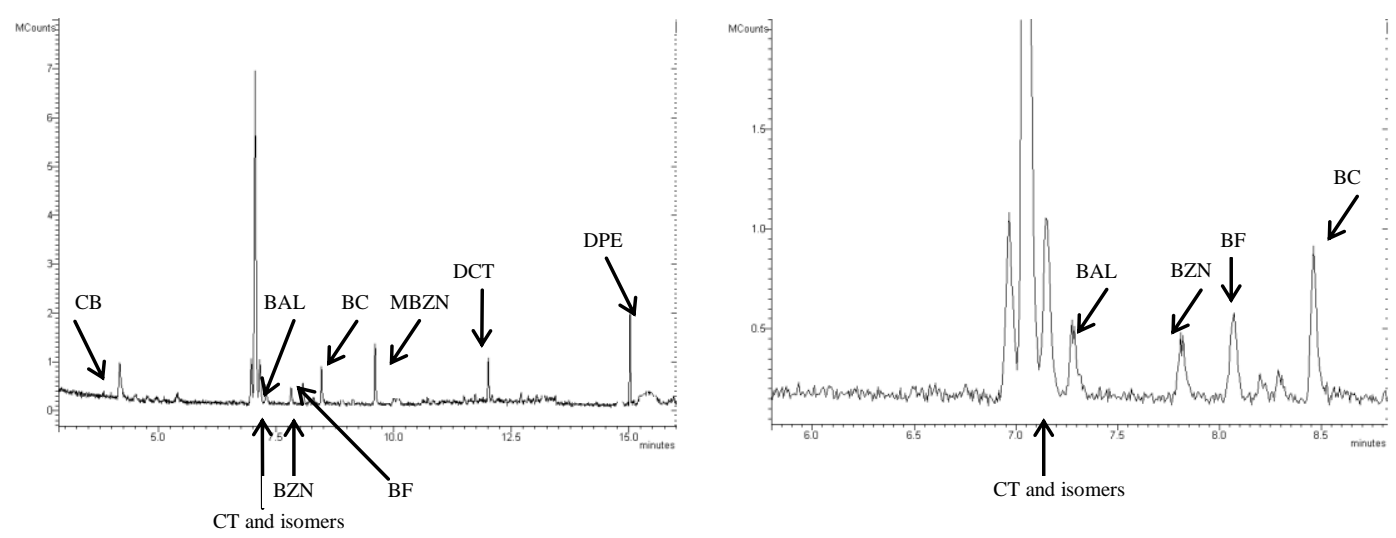

Fig.2. GC-MS analysis of species adsorbed on activated carbon at $550{ }^{\circ} \mathrm{C}$ and zoomed in chromatogram from $6.0-8.5 \mathrm{~min}$

Figure 3 summarises the pathways of the oxidation of alpha-cypermethrin. Our interests in the present study focus on chlorobenzene and diphenyl ether which have been documented and discussed in later sections as important precursors of PCDD/F.

Other significant GC-MS analytes were observed, namely benzonitrile, methyl benzonitrile and benzyl chloride as well as gaseous products identified by FTIR, such as $\mathrm{HCN}$ and $\mathrm{HCl}$ (Fig. 4). Summoogum et al. investigated the effect of $\mathrm{CN}$ group in $\mathrm{O}-\mathrm{CH}(\mathrm{CN})$ bond in alpha-cypermethrin on the initial products of decomposition, by performing density functional theory (DFT) computations. The computations were conducted at the B3LYP/6-31 G (d) level of theory similarly to previous calculations for permethrin. The $\mathrm{O}-\mathrm{CH}_{2}$ and $\mathrm{O}-\mathrm{CHCN}$ bond energies in permethrin and alpha-cypermethrin were 66.1 and $51.4 \mathrm{kcal} \mathrm{mol}^{-1}$ respectively [16]. The optimised cyano structure was planar and showed strong resonance stabilisation between the $\mathrm{NCH}$ - group and the ring. Phenyl radicals arising from the benzene ring were very reactive and combined with the $\mathrm{CN}$ radical to form benzonitrile and methyl benzonitrile at $550{ }^{\circ} \mathrm{C}$. Also, it was found 
that the vinylcyclopropane ring in the thermal decomposition of alpha-cypermethrin aromatised [15] and generated $\mathrm{HCl}$ gas at lower temperatures (Fig. 4), but, at $550{ }^{\circ} \mathrm{C}$, this mechanism was no longer dominating and $\mathrm{Cl}$ radicals were released and reacted with toluene (formed from methyl benzoic acid). Chlorine radicals then reacted with toluene to form benzyl chloride. Benzaldehyde was another product from the aromatisation of alpha-cypermethrin.

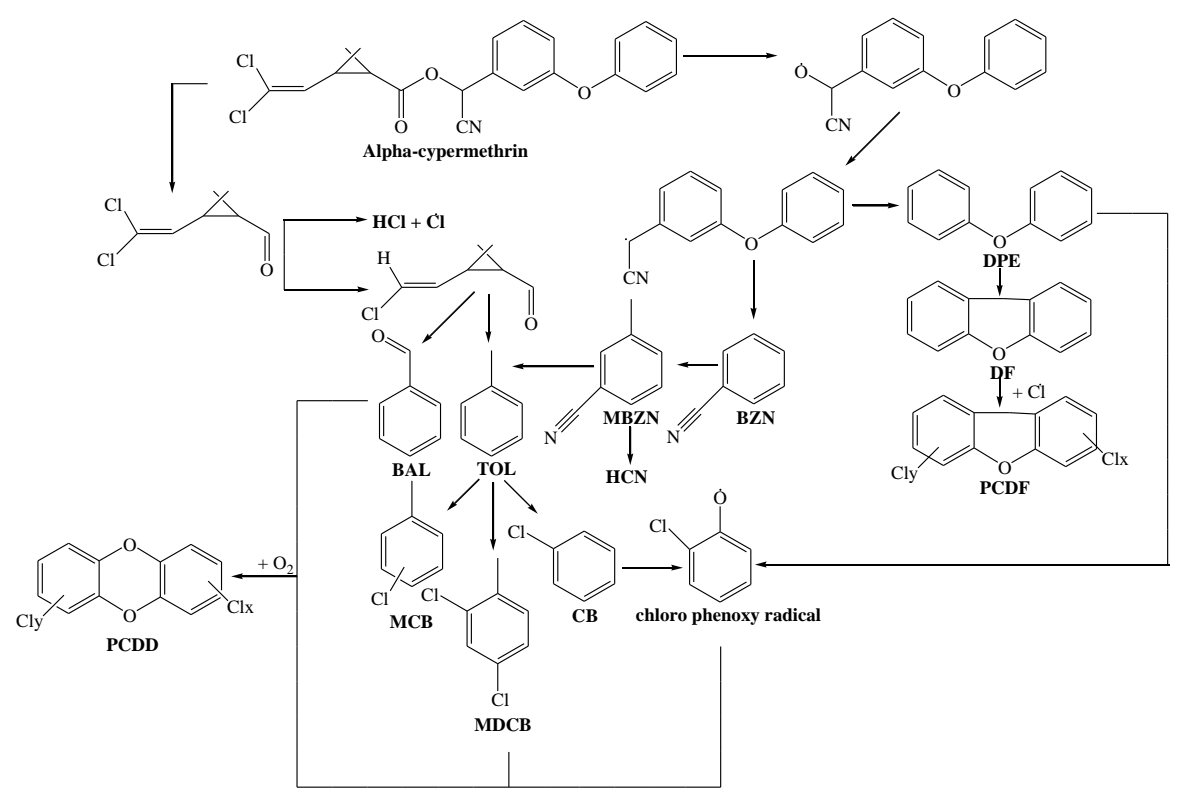

Fig. 3. Pathways of the thermal degradation of alpha-cypermethrin.
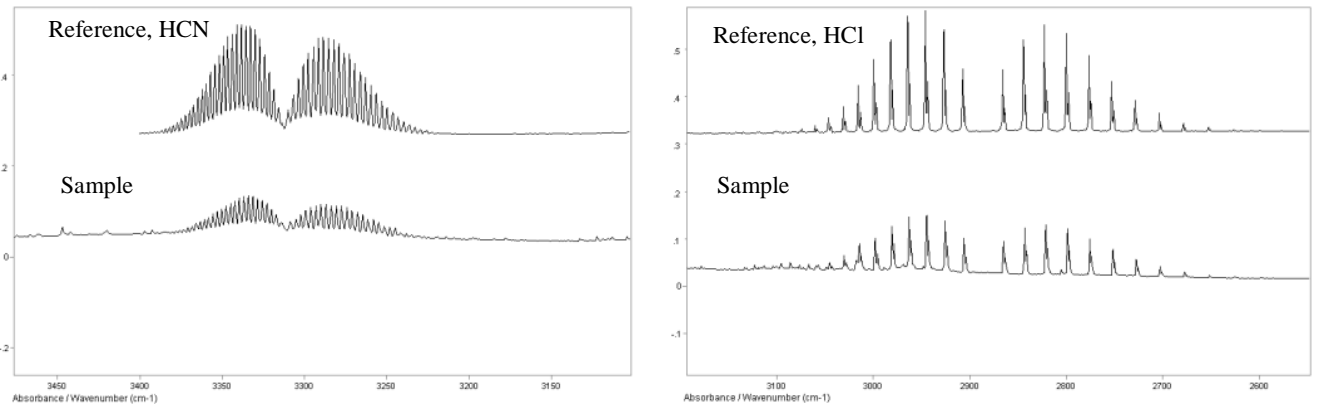

Fig. 4. FTIR spectrum of $\mathrm{HCN}$ and $\mathrm{HCl}$ at $550{ }^{\circ} \mathrm{C}$.

In the experiments, we detected congeners representing all homologue groups of PCDD/F with the exception of OCDF and OCDD. Figure 4 shows the trend in the homologue groups of PCDD/F at a temperature of $550{ }^{\circ} \mathrm{C}$ and a residence time of $1 \mathrm{~s}$. We observed significant amounts of dioxins at $550^{\circ} \mathrm{C}$. An average (for two experiments) total dioxins emissions amounted to $141 \mu^{\mathrm{g} \mathrm{g}^{-1}}$ (RSD $24 \%$ ) of alpha-cypermethrin, at $550{ }^{\circ} \mathrm{C}$. The total PCDF formation was favoured over that of PCDD by a maximum factor of 11, with the ratio of pentachlorinated furans over pentachlorinated dioxins being the least (factor of 1.5). Also, the emission factor of toxic PCDD/F congeners in the analysed sample was $1630 \mathrm{pg} \mathrm{g}^{-1}$ with $385 \mathrm{pg} \Sigma \mathrm{TEQ}-\mathrm{WHO}_{2005} \mathrm{~g}^{-1}$ of alpha-cypermethrin (Table 1). 

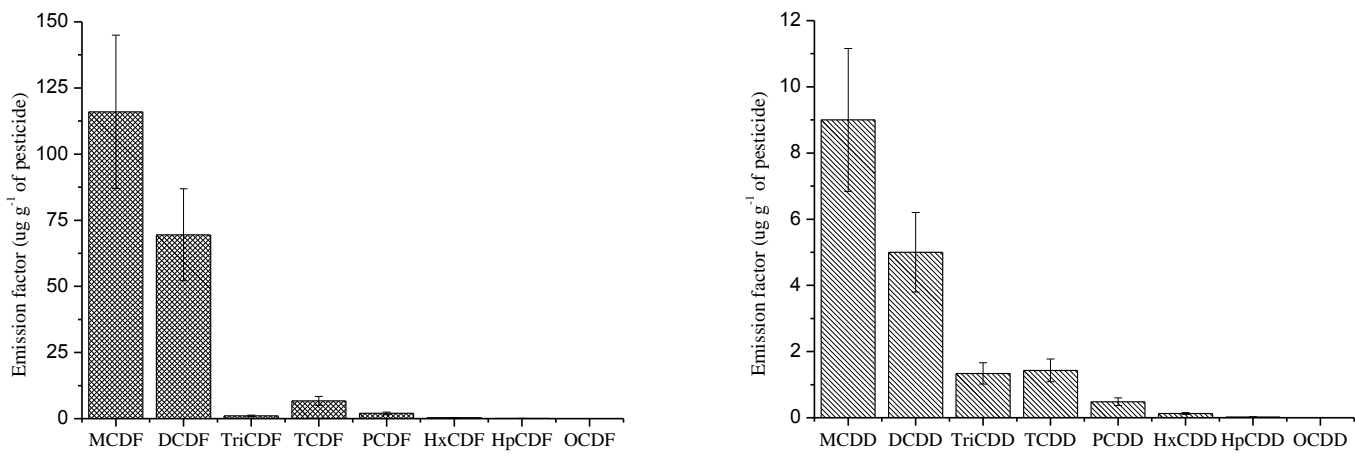

Fig. 5. Emission factor of $\mathrm{PCDF}$ and $\mathrm{PCDD}$ at $550^{\circ} \mathrm{C}$ and at a reactor residence time of $1 \mathrm{~s}$.

Table 1. Emission factor $\left(\mathrm{pg} \mathrm{g}^{-1}\right)$, pg TEQ-WHO $\mathrm{WH}_{2005}\left(\mathrm{~g}^{-1}\right)$ and \% recovery of toxic congeners at $550^{\circ} \mathrm{C}$ at a reactor residence time of $1 \mathrm{~s}$.

\begin{tabular}{|c|c|c|c|}
\hline Congener & $\begin{array}{c}\text { Emission factor } \\
\operatorname{pg~g}^{-1}( \pm \text { SD) of alpha- } \\
\text { cypermethrin }\end{array}$ & $\begin{array}{l}\text { pg TEQ-WHO } \\
\text { of alpha-cypermethrin }\end{array}$ & $\begin{array}{c}\text { Recovery Standard } \\
(\%)\end{array}$ \\
\hline 2,3,7,8-TCDD & $8.56( \pm 0.71)$ & 8.56 & 68.0 \\
\hline 2,3,7,8-TCDF & $191( \pm 2.1)$ & 19.1 & 80.6 \\
\hline $1,2,3,7,8-\mathrm{PCDD}$ & $28.6( \pm 1.0)$ & 28.6 & 85.5 \\
\hline $1,2,3,7,8-\mathrm{PCDF}$ & $53.7( \pm 1.9)$ & 1.61 & 73.3 \\
\hline $2,3,4,7,8-\mathrm{PCDF}$ & $1000( \pm 1)$ & 301 & 65.0 \\
\hline $1,2,3,4,7,8-\mathrm{HxCDD}$ & $5.02( \pm 0.24)$ & 0.502 & 53.4 \\
\hline $1,2,3,6,7,8-\mathrm{HxCDD}$ & $5.61( \pm 0.27)$ & 0.561 & 52.4 \\
\hline $1,2,3,7,8,9-\mathrm{HxCDD}$ & $36.2( \pm 1.6)$ & 3.62 & N/A \\
\hline $1,2,3,4,7,8-\mathrm{HxCDF}$ & $50.6( \pm 0.7)$ & 5.06 & 55.0 \\
\hline $1,2,3,6,7,8-\mathrm{HxCDF}$ & $49.2( \pm 0.9)$ & 4.92 & 52.5 \\
\hline $2,3,4,6,7,8-\mathrm{HxCDF}$ & $46.8( \pm 1.5)$ & 4.68 & 50.0 \\
\hline $1,2,3,7,8,9-\mathrm{HxCDF}$ & $53.6( \pm 1.6)$ & 5.36 & 60.0 \\
\hline $1,2,3,4,6,7,8-\mathrm{HpCDD}$ & $15.7( \pm 2.6)$ & 0.157 & 49.8 \\
\hline 1,2,3,4,6,7,8-HpCDF & $74.1( \pm 2.1)$ & 0.741 & 51.7 \\
\hline $1,2,3,4,7,8,9-\mathrm{HpCDF}$ & $7.44( \pm 0.35)$ & 0.074 & 61.9 \\
\hline OctaCDD & n.d & n.d & 54.8 \\
\hline OctaCDF & n.d & n.d & N/A \\
\hline Total & 1630 & 385 & - \\
\hline
\end{tabular}

n.d. - not detected, below limit of detection

N/A - not applicable as $1,2,3,7,8,9-{ }^{13} \mathrm{C}-\mathrm{HxCDD}$ and ${ }^{13} \mathrm{C}$-OctaCDF are not present in recovery standard.

$\mathrm{TCDD} / \mathrm{F}, \mathrm{PCDD} / \mathrm{F}, \mathrm{HxCDD} / \mathrm{F}, \mathrm{HpCDD} / \mathrm{F}$ and OctaCDD/F denote tetra, penta, hexa, hepta and octa chlorinated dibenzo- $p$-dioxins and dibenzofurans

The identification of reference isomers within the homologue groups follows the injection of genuine standards and the published elution order. 1-MCDF is the most abundant isomer in the MCDF homologue group as shown in Fig. 6, followed by 3-MCDF, 2-MCDF and last 4-MCDF while 1-MCDD dominates the distribution of MCDD. For higher congeners such as TCDD, we injected 1,2,3,4-TCDD and 2,3,7,8-TCDD as shown in Fig. 7 and then used published elution order from Fishman et al. and Hale et al. to identify and determine the yield of the rest of the congeners [19,20]. 

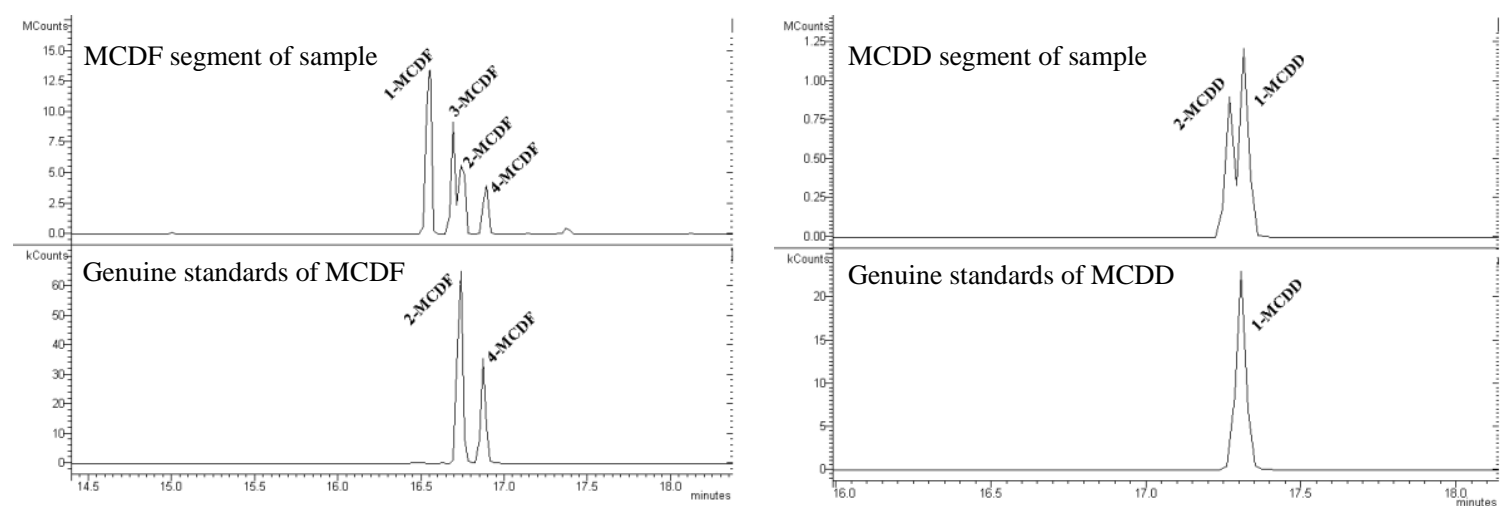

Fig. 6. GC-MS/MS chromatogram of the MCCF and MCDD segment of experimental sample and genuine standards of MCCF and MCDD.

Under oxidative conditions, $\mathrm{OH}$ and $\mathrm{Cl}$ radicals are the major carriers, favouring the formation of $\mathrm{PCDD} / \mathrm{F}$ over dibenzo- $p$-dioxin and dibenzofuran (DD/F) by abstraction of $\mathrm{H}$ radicals through diketo- and etherintermediates [6,9]. Because of the structure of DPE and DF, PCDF are the preferred products from DPE. This pathway still competes with the parent molecule that can decompose to give phenoxy radicals. PCDD/F generated from the oxidation of alpha-cypermethrin can also result directly from substitution of $\mathrm{Cl}$ in DPE fragments prior to the closure of the furan or dioxin ring. Ross et al. and Lindahl et al. investigated similar reaction steps using polychlorinated diphenyl ether isomers and their PCDD and PCDF products $[21,22]$. PCDPE with a $\mathrm{Cl}$ ortho to the bridging oxygen demonstrated much greater conversions to PCDF. The ability of DPE, phenoxy and chlorophenoxy to behave as PCDD/F precursors is covered in the next sections.

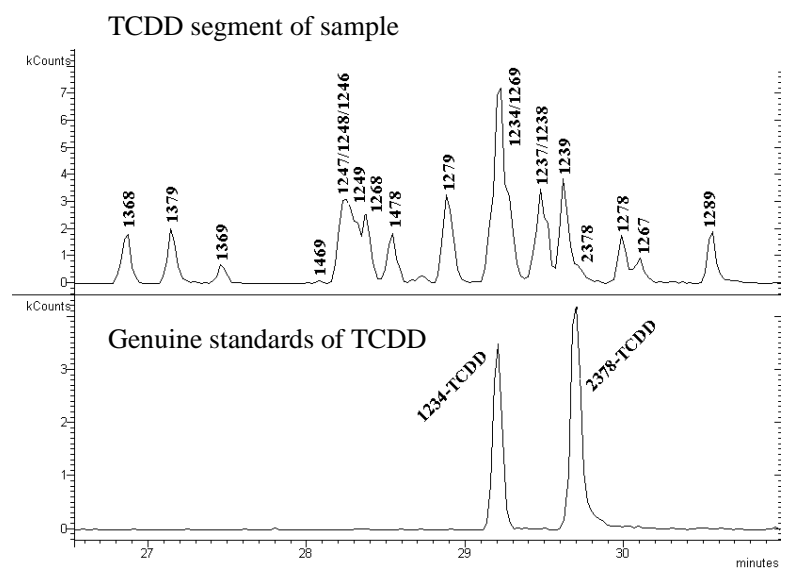

Fig. 7. GC-MS/MS chromatogram of the TCDD segment of experimental sample and genuine standards of TCDD.

\section{Formation of Phenyl, Phenoxy Radicals and Chlorophenoxy Radicals}

Many researchers studied the combustion of chlorobenzene which can form phenol and chlorophenols [6,7, ,10], reporting these species as an important group of precursors to PCDD/F. Consequently, we attempted to identify phenols in the exhaust gases. The product gas was bubbled into a chilled solvent trap $\left(0{ }^{\circ} \mathrm{C}\right)$ containing 1:1 v/v DCM and acetone, similarly as carried out previously in our laboratory for the pyrolysis of alpha-cypermethrin. We detected no phenols, unlike in the product from the pyrolysis experiments. Although we installed silica gel adsorber, which was extracted by methanol according to OSHA 32, no phenol was detected. 
Since we observed no phenol or phenolic compounds, the formation of PCDD/F must be due to other precursors such as phenyl and phenoxy radicals, formed from toluene as illustrated in Fig. 8(a). The reaction initiates by abstraction of an $\mathrm{H}$ by molecular oxygen [23]. The resulting hydrocarbon radical, benzyl, reacts with oxygen forming a benzylperoxy radical. A number of decomposition paths of the benzylperoxy radical can lead to different product species from the removal of the side methylene $\left(\mathrm{CH}_{2}\right)$ group. This removal forms directly phenoxy radical. We observed benzaldehyde which is formed from the isomerisation of this radical, via the transfer of $\mathrm{H}$ from $\mathrm{C}$ to $\mathrm{O}$, scission of $\mathrm{O}-\mathrm{O}$ bond to produce $\mathrm{OH}$, and finally the expulsion of $\mathrm{H}$ [24]. $\mathrm{OH}$ produced makes the system more reactive. The side chain cleaves again to produce phenyl, $\mathrm{C}_{6} \mathrm{H}_{6}$, or phenoxy, $\mathrm{C}_{6} \mathrm{H}_{6} \mathrm{O}$, radical.

The formation of chlorophenoxy radicals commences with the initial decomposition step of monochlorobenzene as shown in Fig. 8(b), involving the abstraction or ejection of $\mathrm{H}$ or $\mathrm{Cl}$ directly from benzene ring. $\mathrm{Cl}$ more readily abstracts $\mathrm{H}$ than the $\mathrm{Cl}$ atom in monochlorophenol (MCP). If sufficient oxygen is present in the system, it competes with chlorine in attacking the available radical site to form three chlorophenoxyperoxy radicals. The main exit channel for chlorophenoxyperoxy is through the departure of the terminal oxygen atom of the peroxy group, or $\mathrm{OH}$ radical from - $\mathrm{OOH}$ group produced by isomerisation of chlorophenoxyperoxy, to form three chlorophenoxy radicals [25]. Although we could not identify the phenol and chlorophenols, we expect that the phenoxy and chlorophenoxy radicals are easily produced in our experiments, owing to the availability of $\mathrm{Cl}$ from the decomposition of alphacypermethrin.
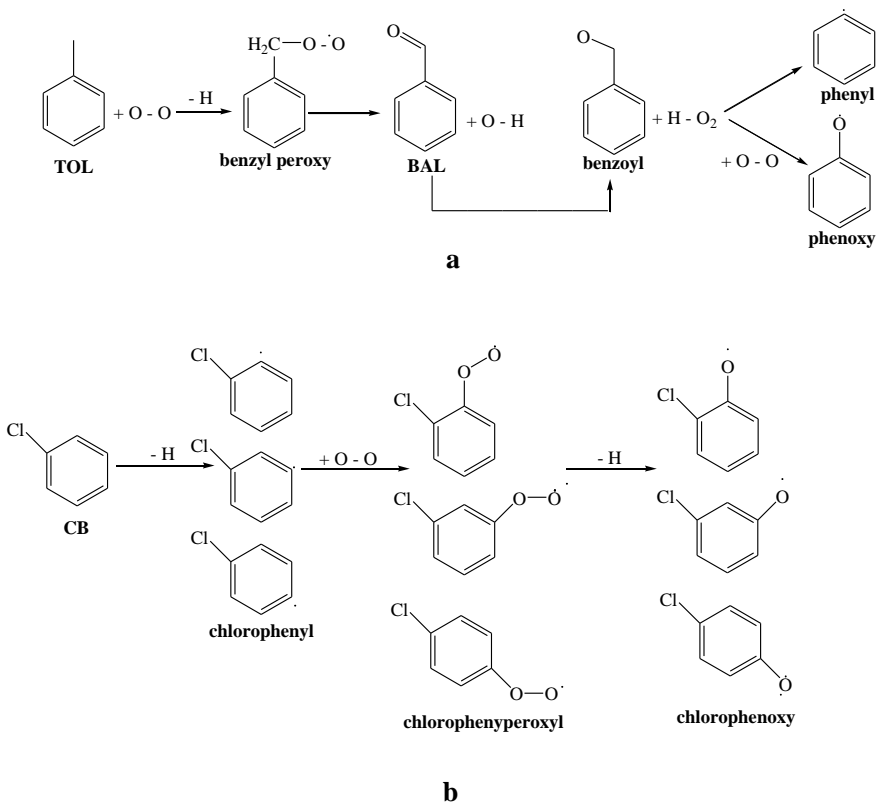

Fig. 8. Phenoxy: (a) chlorophenoxy; (b) routes from CB.

\section{Formation of 1-MCDD over DD}

The recombination of the oxygen-centred 2-chlorophenoxy radical with the carbon (hydrogen) centred radical has been widely documented to form a keto-ether [7,9,10]. Two kinds of oxygen-carbon coupling modes exist, as represented in Fig. 9, namely the coupling of the phenolic oxygen with the ortho carbon bonded to hydrogen of a second (chloro) phenoxy radical $(\mathrm{O} / \mathrm{CH})$, and the coupling of the phenolic oxygen with the ortho carbon bonded to chlorine of a second (chloro) phenoxy radical $(\mathrm{O} / \mathrm{CCl})$. The first pathway includes the elementary processes of $\mathrm{O} / \mathrm{CH}$ coupling, $\mathrm{Cl}$ abstraction, and intra-annular elimination of $\mathrm{H}$. In the study, we detected no DD but observed significant amount of 1-MCDD compared to the other congeners of dioxins. Similarly, the formation of 2-MCDD may be attributed to the reaction of 
corresponding phenoxy radicals. A higher yield of 1-MCDD than that of 2-MCDD confirms that the ortho position of $\mathrm{CB}$ is more active than in meta and para positions.

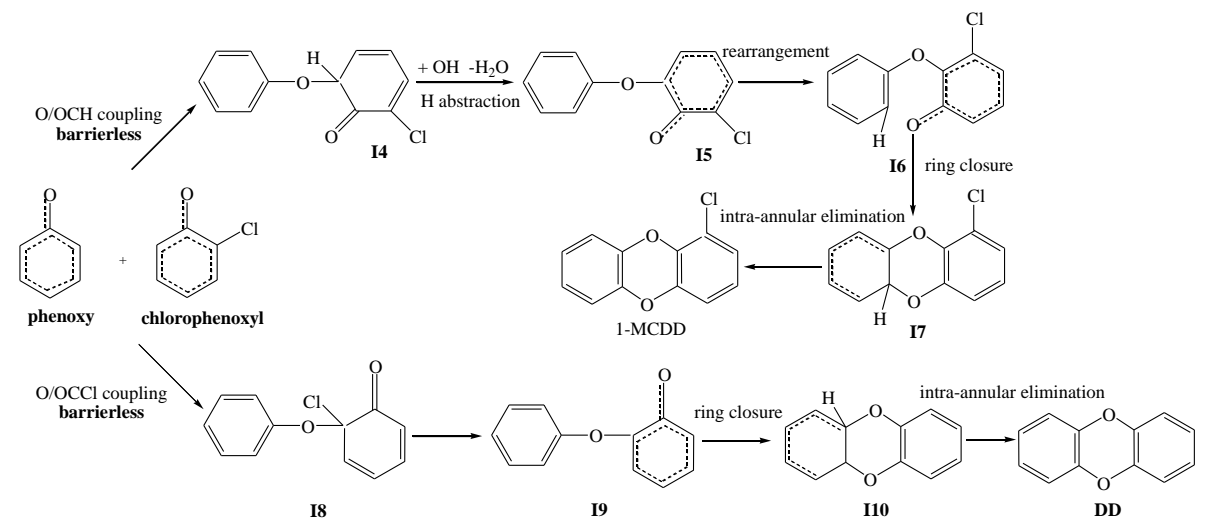

Fig. 9. A mechanistic pathway for the formation of 1-MCDD from phenoxy and chlorophenoxy [10].

\section{Formation of Monochlorodibenzofurans}

1-MCDF dominates the congener profile within its homologue group. 1-MCDF can form along several pathways such as from phenoxy and 3-chlorophenoxy, from benzene and 3-chlorophenoxy and from precursors having DPE moiety. However, because of the abundance of DPE and absence of benzene, we postulate that the formation of 1-MCDF proceeds through the formation of DPE as shown in Fig. 10. The $\mathrm{CN}$ group makes the molecule more reactive and as $\mathrm{CN}$ is expelled from $\mathrm{I11}$ to form I12, oxygen then adds to $\mathrm{I} 12$, the resulting molecule isomerises with $\mathrm{H}$ attaching to the peroxy group, with subsequent breakage of the $\mathrm{O}-\mathrm{O}$ bond to liberate $\mathrm{OH}$ radical. The $\mathrm{CH}_{3}$ group in $\mathrm{I} 13$ is replaced by $\mathrm{H}$ to form $\mathrm{I} 14$. Further steps are summarised in Fig. 10.

The formation of 4-MCDF, which has been reported by many researchers, proceeds by the recombination of phenoxy and 2-chlorophenoxy, through either the carbon (hydrogen) centred radical with the carbon (chlorine) centred radical or through the former chlorophenoxy radical with unchlorinated carbon-centred radical. However, in the case of alpha-cypermethrin, the concentration of diphenyl ether is higher than that of chlorobenzene. For this reason, the concentration of 1-MCDF is found to dominate the congener profile in this homologue group; i.e., 1-MCDF > 3-MCDF > 2-MCDF > 4-MCDF.

Because of the presence of 2-chlorophenol, formation of 4-MCDF can proceed through DPE as well as phenoxy and 2-chlorophenoxy. However, for other congeners, 2-MCDF and 3-MCF are formed from DPE instead of phenoxy and 3-chlorophenoxy and 4-chlorophenoxy respectively as the ortho position is more active than in the meta and para positions. Also, the abundance of DPE is one of the reasons why MCDF predominates over MCDD.

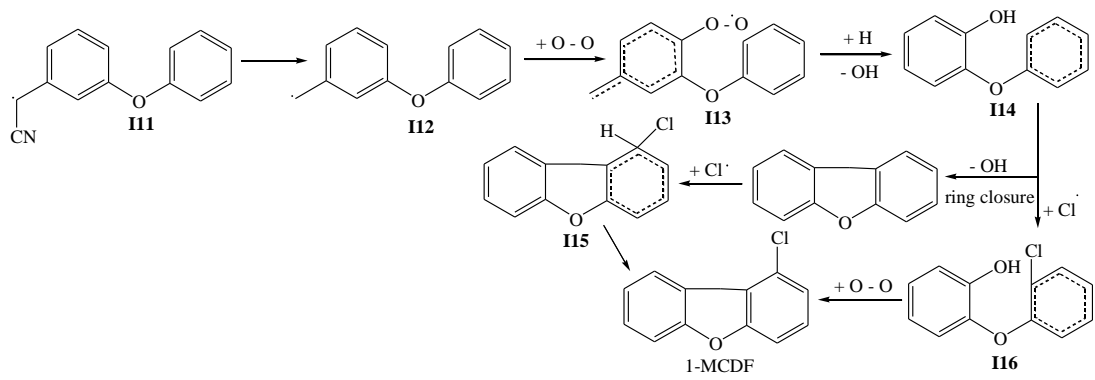

Fig. 10. Formation of 1-MCDF, [11,22,26]. 


\section{Yield and Distribution of PCDD/F as Function of Residence Time}

In this study, we injected genuine standards of 2-MCDF, 4-MCDF, 1-MCDD, 2,3-DCDF, 1,3-DCDD, 2,7DCDD, 2,3-DCDD, 2,4,8-TriCDF, 2,3,7-TriCDD, 2,3,7,8-TCDF, 1,2,3,4-TCDD, 2,3,7,8-TCDD, 1,2,3,7,8PCDF, 2,3,4,7,8-PCDF, 1,2,3,7,8-PCDD, 1,2,3,4,7,8-HxCDF, 1,2,3,6,7,8-HxCDF, 2,3,4,6,7,8-HxCDF, 1,2,3,7,8,9-HxCDF, 1,2,3,4,7,8-HxCDD, 1,2,3,6,7,8-HxCDD, 1,2,3,7,8,9-HxCDD, 1,2,3,4,6,7,8-HpCDF, $1,2,3,4,7,8,9-\mathrm{HpCDF}, 1,2,3,4,6,7,8-\mathrm{HpCDD}$, OCDF and OCDD. The identification of the remaining congeners was based on literature measurements of their retention order on the same column, VF-5 ms and DB-5 ms [19]. We took care in building analytical methods to allow the detection of all congeners, using additional windows defining standards.

We have quantified dioxins in each homologue group and have observed that the concentration of PCDF exceeded that of PCDD at $550^{\circ} \mathrm{C}$. The yields of PCDF such as TriCDF, TCDF, PCDF, HxCDF, HpCDF were $10.8,6.73,2.01,0.314,0.08 \mu \mathrm{g} \mathrm{g}^{-1}$ alpha-cypermethrin and were higher than the chlorinated DD by a factor of 4-8, as illustrated in Table 2. Both the distribution and yield of homologue group of PCDD/F exhibited decreasing trend with shorter residence time. The absence of trichlorobenzene and methyl trichlorobenzene in VOC analyses and the presence of all congeners with the exception of OCDF and OCDD suggest the chlorination of TriCDF, TCDF, PCDF, HxCDF or further chlorination of methyl dichlorophenoxy radicals during their coupling to chlorobenzene, leading to TCDF, PCDF and HxCDF. Longer residence time increases the extent of chlorination, shifting the distribution of PCDD/F to more chlorinated homologue groups (Table 2). The ratio of chlorinated DF to chlorinated DD remains approximately the same within each homologue group varying from 3 to 13 for $5 \mathrm{~s}$, and 1.5 to 11 for $1 \mathrm{~s}$ residence time. This indicates that the residence time does not change the reaction pathways responsible for generation, oxidation, chlorination and dechlorination of dioxins.

Table 2. Emission factors for $\mathrm{PCDD} / \mathrm{F}$ as determined from experiments performed at $550{ }^{\circ} \mathrm{C}$ at residence time (RT) of 5 and $1 \mathrm{~s}$, respectively.

\begin{tabular}{|c|c|c|}
\hline $\begin{array}{l}\text { PCDD/F } \\
\text { homologue group }\end{array}$ & $\begin{array}{c}\text { Emission factor at RT } 5 \mathrm{~s} \\
\left(\mu \mathrm{g} \mathrm{g} \mathrm{g}^{-1} \text { of alpha- }\right. \\
\text { cypermethrin) }\end{array}$ & $\begin{array}{c}\text { Emission factor at RT } 1 \mathrm{~s} \\
\left(\mu \mathrm{g}^{-1} \text { of alpha- }\right. \\
\text { cypermethrin) }\end{array}$ \\
\hline MCDF & 116 & 98.6 \\
\hline MCDD & 9.05 & 9.14 \\
\hline DCDF & 69.5 & 23.4 \\
\hline DCDD & 5.00 & 2.12 \\
\hline TriCDF & 10.8 & 0.179 \\
\hline TriCDD & 1.34 & 0.396 \\
\hline TCDF & 6.73 & 4.52 \\
\hline TCDD & 1.43 & 0.792 \\
\hline PCDF & 2.01 & 1.09 \\
\hline PCDD & 0.484 & 0.328 \\
\hline $\mathrm{HxCDF}$ & 0.314 & 0.349 \\
\hline HxCDD & 0.127 & 0.234 \\
\hline HpCDF & 0.079 & 0.049 \\
\hline HpCDD & 0.021 & 0.038 \\
\hline OCDF & n.d & n.d \\
\hline OCDD & n.d & n.d \\
\hline TOTAL & 223 & 141 \\
\hline
\end{tabular}

n.d. - not detected or below limit of detection

MCDD/F, DCDD/F, TriCDD/F, TCDD/F, PCDD/F, HxCDD/F, HpCDD/F and OctaCDD/F denote mono, $\mathrm{di}$, tri, tetra, penta, hexa, hepta and octa chlorinated dibenzo- $p$-dioxins and dibenzofurans

However, this may not reflect the yields obtainable under actual fire conditions as bench scale experiments cannot replicate all aspects of real fires. The formation of toxic products depends mainly on equivalence 
ratio and mode of combustion. In this study, we employed an oxygen concentration of $5.5 \%$ which corresponds to fuel lean condition with an equivalence ratio of 0.04 . We have carried out further study to cover a range of well-ventilated, stoichiometric and under-ventilated combustion by adjusting the equivalence ratio $(\Phi)$ to $0,0.65,1.00,2.25$ and 6.50 , to investigate the effect of these combustion conditions on the emission factors of mono to octa chlorinated dibenzo-p-dioxins and dibenzofurans as well as on the TEQ of the toxic congeners. Our experimental results indicate a maximum yield of polychlorinated dibenzo- $p$-dioxins and polychlorinated dibenzofurans to occur at $5.5 \%$ oxygen $(\Phi=0.04)$, consistently with similar measurements reported in literature [5]. We have also observed that the minimum formation of $\mathrm{PCDD} / \mathrm{F}$ occurs for an equivalence ratio of 6.5 . The detailed results of this further study will be presented in a follow-up manuscript.

\section{CONCLUSIONS}

In this contribution, we have determined the pathways of formation of PCDD/F during oxidation of alphacypermethrin, a common pyrethroid insecticide. The VOC analyses detected no phenol or chlorophenols but revealed chlorobenzenes, isomers of chlorotoluene, and diphenyl ether as the PCDD/F precursors at $550^{\circ} \mathrm{C}$. We have determined the emission factors of PCDD/F using HRGC-ITMS analyses and unravelled routes from their precursors. In particular, we have described the formation pathways of the dominating congeners namely 1-MCDD and 1-MCDF. The oxidation of alpha-cypermethrin favours the formation of PCDF compared to PCDD, by a maximum factor of 11 (depending on the homologue group) with the total yield of PCDD/F increasing with residence time. The emission factors of VOC and PCDD/F presented in this contribution allow an assessment of the amount of the toxic pollutants emitted from chemical fires of alpha-cypermethrin and similar pyrethroids insecticides. The results could also be used to estimate the amount of pollutants formed in combustion of biomass contaminated with alpha-cypermethrin and similar pyrethroids insecticides.

\section{ACKNOWLEDGEMENTS}

This study was supported by the Australian Research Council. We acknowledge with gratitude the advice received from Assistant Professor Mohammednoor Altarawneh of Al-Hussein Bin Talal University, Jordan. SLS thanks the University of Newcastle for a postgraduate research scholarship.

\section{REFERENCES}

[1] Tame, N.W., Dlugogorski, B.Z., and Kennedy, E.M., (2005) PCDD/F Formation in Flaming Combustion, Smouldering, and Oxidative Pyrolysis of Eco-friendly' Treated Wood, Proceedings of the Combustion Institute 30: 1237-1243, http://dx.doi.org/10.1016/j.proci.2004.08.008

[2] Tame, N.W., Dlugogorski, B.Z., and Kennedy, E.M., (2007) Formation of Polychlorinated Dibenzo- $p$-Dioxins and Polychlorinated Dibenzofurans (PCDD/F) in Fires of Arsenic-Free Treated Wood: Role of Organic Preservatives, Environmental Science and Technology 41: 64256432, http://dx.doi.org/10.1021/es0703980

[3] Tame, N.W., Dlugogorski, B.Z., and Kennedy, E.M., (2007) Formation of Dioxins and Furans during Combustion of Treated Wood, Progress in Energy and Combustion Science 33: 384-408, http://dx.doi.org/10.1016/j.pecs.2007.01.001

[4] US EPA., (2002) Emissions of Organic Air Toxics from Open Burning, National Risk Management, Research Laboratory, http://dx.doi.org/10.1016/j.pecs.2003.08.001

[5] Addink, R., and Olie, K., (1995) Role of Oxygen in Formation of Polychlorinated Dibenzo-pDioxins/Dibenzofurans from Carbon on Fly Ash, Environmental Science and Technology 29: 1586-1590, http://dx.doi.org/10.1021/es00006a023

[6] Altarawneh, M., Kennedy, E.M., Dlugogorski, B.Z., and Mackie, J.C., (2007) Quantum Chemical Investigation of Formation of Polychlorodibenzo-p-dioxins and Dibenzofurans from Oxidation 
and Pyrolysis of 2-chlorophenol, Journal of Physical Chemistry A 111: 2563-2573, http://dx.doi.org/10.1021/jp065558t

[7] Zhang, Q., Li, S., Qu, X., Shi, X., and Wang, W., (2008) Quantum Mechanical Study on the Formation of PCDD/F from 2-Chlorophenol as Precursor, Environmental Science and Technology 42: 7301-7308, http://dx.doi.org/10.1021/es801599n

[8] Wiater, I., and Louw, R., (1999) Reactions of Diphenyl Ether with Chlorine and Bromine Atoms around $750 \mathrm{~K}$ - Relevance for Gas-Phase "Dioxin" Formation, European Journal of Chemistry, 261-265, http://dx.doi.org/10.1002/(SICI)1099-0690(199901)1999:1<261::AID-EJOC261 >3.0. CO:2-I

[9] Evans, C.S., and Dellinger, B., (2005) Mechanisms of Dioxin Formation from the HighTemperature Oxidation of 2-chlorophenol, Environmental Science and Technology 39: 122-127, http://dx.doi.org/10.1021/es049355z

[10] Xu, F., Yu, W., Gao, R., Zhou, Q., Zhang, Q., and Wang, W., Dioxin Formations from the Radical/Radical Cross-Condensation of Phenoxy Radicals with 2-chlorophenoxy Radicals and 2,4,6-Trichlorophenoxy Radicals, Environmental Science and Technology 44: 6745-6751, http://dx.doi.org/10.1021/es101794v

[11] Altarawneh, M., Kennedy, E.M., Dlugogorski, B.Z., and Mackie, J.C., (2007) Theoretical Study of Reaction Pathways of Dibenzofuran and Dibenzo-p-Dioxin under Reducing Conditions, Journal of Physical Chemistry A 111: 7133-7140, http://dx.doi.org/10.1021/jp071166q

[12] Wikstrom, E., and Marklund, S., (2000) Secondary Formation of Chlorinated Dibenzo-p-Dioxins, Dibenzofurans, Biphenyls, Benzenes, Benzenes, and Phenols during MSW Combustion, Environmental Science and Technology 34: 604-609, http://dx.doi.org/10.1021/es9906498

[13] Hyong, D., and Mulholland, J.A., (2005) Temperature-Dependent Formation of Polychlorinated Naphthalenes and Dibenzofurans from Chlorophenols, Environmental Science and Technology 39: 5831-5836, http://dx.doi.org/10.1021/es050576u

[14] Vikelsøe, J., and Johansen, E., (2000) Estimation of Dioxin Emission from Fires in Chemicals, Chemosphere 40: 165-175, http://dx.doi.org/10.1016/S0045-6535(99)00231-3

[15] Summoogum, S.L., Dlugogorski, B.Z., Altarawneh, M., Mackie, J.C., and Kennedy, E.M., "Decomposition of Dibenzo-p-Dioxin in Fires," Sixth International Seminar on Fire and Explosion Hazards, University of Leeds, UK, 2010, pp.213-225.

[16] Summoogum, S.L., Mackie, J.C., Kennedy, E.M., Delichatsios, M.A., and Dlugogorski, B.Z., Thermal Decomposition of Alpha-Cypermethrin under Non-Oxidative Conditions, Submitted in Chemosphere.

[17] Summoogum, S.L., Mackie, J.C., Kennedy, E.M., and Dlugogorski, B.Z., "Pyrolysis and Decomposition Pathways of Alphacypermethrin under Non-Oxidative Conditions," Proceedings of the Australian Combustion Symposium, University of Queensland, 2009, pp. 123-126.

[18] Chen, K., Wojtalewicz, D.A., Altarawneh, M., Dlugogorski, B.Z., Mackie, J.C., and Kennedy, E.M., (2010) Formation of Polychlorinated Dibenzo-p-Dioxins and Dibenzofurans (PCDD/F) in Oxidation of Captan Pesticide, Proceedings of the Combustion Institute Beijing, 33: 701-708 http://dx.doi.org/10.1016/j.proci.2010.07.069

[19] Fishman, V., Martin, G., and Lamparski, L., (2007) Comparison of a Variety of Gas Chromatographic Columns with Different Polarities for the Separation of Chlorinated Dibenzo-pdioxins and Dibenzofurans by High-Resolution Mass Spectrometry, Journal of Chromatography 1139: 285-300, http://dx.doi.org/10.1016/j.chroma.2006.11.025

[20] Hale, M., Hileman, F., Mazer, T., Shell, T., Noble, R., and Brooks, J., (1985) Mathematical Modelling of Temperature Programmed Capillary Gas Chromatographic Retention Indexes for 
Polychlorinated Dibenzofurans, Analytical Chemistry 57: 640-648, http://dx.doi.org/10.1021/ac00280a017

[21] Ross, B.J., Naikwadi, K.P., and Karasek, F.W., (1989) Effect of Temperature, Carrier gas, and Precursor Structure on PCDD and PCDF Formed from Precursors by Catalytic Activity of MSW Incinerator Fly Ash, Chemosphere 19: 291-298, http://dx.doi.org/10.1016/0045-6535(89)90326-3

[22] Lindahl, R., Rappe, C., and Buser, H.R., (1980) Formation of Polychlorinated Dibenzofurans (PCDFs) and Polychlorinated Dibenzo-p-Dioxins (PCDDs) from the Pyrolysis of Polychlorinated Diphenyl Ethers, Chemosphere 9: 351-361, http://dx.doi.org/10.1016/0360-1285(86)90011-0

[23] Brezinsky, K., (1986) The High Temperature Oxidation of Aromatic Hydrocarbons, Progress in Energy and Combustion Science 12: 1-24

[24] Gorkum, R.V., and Bouwman, E., (2005) The Oxidative Drying of Alkyd Paint Catalysed by Metal Complexes, Coordination Chemistry Reviews 249: 1709-1728, http://dx.doi.org/10.1016/j.ccr.2005.02.002

[25] Altarawneh, M., Kennedy, E.M., Dlugogorski, B.Z., and Mackie, J.C., Mechanisms for PCDF and PCB Formations from Fires: Pathways from Oxidation of Chlorobenzenes, Proceedings $7^{\text {th }}$ AsiaOceania Symposium on Fire Science and Technology, Hong Kong, 2007.

[26] Altarawneh, M., Carrizo, D, Ziolkowski, A, Kennedy, E.M., Dlugogorski, B.Z., and Mackie, J.C., (2009) Pyrolysis of Permethrin and Formation of Precursors of Polychlorinated Dibenzo-pDioxins and Dibenzofurans (PCDD/F) under Non-Oxidative Conditions, Chemosphere 74: 14351443, http://dx.doi.org/10.1016/j.chemosphere.2008.12.033 
Table 3. Limits of detection and quantification of PCDD/F.

\begin{tabular}{|l|c|c|}
\hline Native PCDD\&PCDF & LOD $\left(\mathbf{p g} \boldsymbol{\mu} \mathbf{L}^{-\mathbf{1}}\right)$ & $\mathbf{L O Q}\left(\mathbf{p g} \boldsymbol{\mu \mathbf { L } ^ { - 1 }}\right)$ \\
\hline 2-MCDF & 0.2 & 0.6 \\
\hline 2-MCDD & 0.2 & 0.8 \\
\hline 2,3-DCDF & 0.2 & 0.7 \\
\hline 2,8-DCDD & 0.3 & 1.1 \\
\hline 2,3,7-TriCDD & 0.3 & 1.0 \\
\hline $2,3,7,8-\mathrm{TCDD}$ & 0.3 & 1.1 \\
\hline $2,3,7,8-\mathrm{TCDF}$ & 0.7 & 2.4 \\
\hline $1,2,3,7,8-\mathrm{PeCDD}$ & 2.3 & 7.5 \\
\hline $1,2,3,7,8-\mathrm{PeCDF}$ & 1.7 & 5.6 \\
\hline $2,3,4,7,8-\mathrm{PeCDF}$ & 1.8 & 6.0 \\
\hline $1,2,3,4,7,8-\mathrm{HxCDD}$ & 2.0 & 6.7 \\
\hline $1,2,3,6,7,8-\mathrm{HxCDD}$ & 2.9 & 9.7 \\
\hline $1,2,3,7,8,9-\mathrm{HxCDD}$ & 3.0 & 9.9 \\
\hline $1,2,3,4,7,8-\mathrm{HxCDF}$ & 2.1 & 6.9 \\
\hline $1,2,3,6,7,8-\mathrm{HxCDF}$ & 1.4 & 4.5 \\
\hline $2,3,4,6,7,8-\mathrm{HxCDF}$ & 2.0 & 6.5 \\
\hline $1,2,3,7,8,9-\mathrm{HxCDF}$ & 2.6 & 8.6 \\
\hline $1,2,3,4,6,7,8-\mathrm{HpCDD}$ & 2.3 & 7.7 \\
\hline $1,2,3,4,6,7,8-\mathrm{HpCDF}$ & 2.3 & 7.6 \\
\hline $1,2,3,4,7,8,9-\mathrm{HpCDF}$ & 2.1 & 7.0 \\
\hline OctaCDD & 2.9 & 9.6 \\
\hline OctaCDF & 3.6 & 11.7 \\
\hline
\end{tabular}

